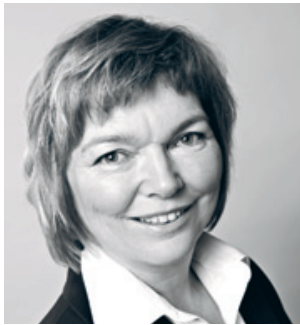

Charlotte Haug (born 1959) is an MD and has an MA degree in health services research from Stanford University. She has been Editor-inChief of the Journal of the Norwegian Medical Association since 2002

Photo: Einar Nilsen

Norway can have the world's best health services for individual patients, for the population as a whole or for the health workers - but not for all of them at the same time. That's wishful thinking.

\section{The best in the world}

Every year I observe at close range one of the best medical environments that I know of, at Stanford University in California. Diagnostics, treatment and care at Stanford Hospital are outstanding, and this hospital has again been ranked as one of the best in the USA. Their medical technology is of top quality, and the hospital recently received an award for having one of the country's most well-functioning IT systems. In addition, Stanford undertakes world-class medical research: Currently, their medical faculty includes three Nobel Prize laureates. To top things off, major emphasis is placed on basic and supplementary training of doctors and other health personnel. The teaching at Stanford University School of Medicine is among the best in the USA, and is also innovative as well as idealistic. Patient treatment, research and teaching are given equal priority, not only on paper, but also in practice.

In addition to observing this medical environment from the perspective of a doctor and researcher, I have followed my colleagues and their children for 15 years through serious and not quite so serious illness. The professional quality of the health services provided and the follow-up of the patients are impressive. There, nobody has to seek out a doctor who should have special responsibility for a particular patient. As a matter of course, the treating doctor follows the patient prior to, during and after his or her hospitalisation - including outside «normal» working hours. It is also self-evident that the patients are treated with respect and dignity, that they are well informed, are provided with alternative options and are included in decisions that pertain to them.

Quite naturally, it is not all a bed of roses. Errors are made, disagreement arises. On the whole, however, patients see that they receive the very best treatment, and the doctors are allowed to exercise their profession according to their best discretionary judgement. Waiting times are counted in minutes and hours, not days and months. Trickery with waiting lists and codes is an unknown phenomenon. Of course, there are those among the health staff who moan about managers and administrators - and vice versa - but this is eons away from the destructive mistrust that currently exists in Norwegian health services.

When we in Norway raise our eyebrows and ascertain that we do not want «American conditions» in Norwegian health services, it is hardly the standard of the patient treatment at Stanford Medical Center that we have in mind. This is top notch and actually looks exactly as the health personnel, the patients and politicians in various camps want it to. So how do they achieve this? Can't we just do it the same way here?

Particularly at the approach of an election we may be left with the impression that «perfect» health services can be had by pulling the right «levers»: professional, organisational, legal or financial. And in Norway we are - at least when seen from the outside - in nearuniversal agreement as to how these perfect health services should be: strong, publicly funded health services of high quality, with equal availability for all, in which good, professional priorities - at least in theory - guide the services provided to the patients. Nobody wants unnecessary bureaucracy, but we also want professionals to be freed from «administrative» duties. We want minimal queues and short waiting times, combined with freedom of choice for patients, for example a free choice of hospital. We realise that we need an element of private enterprise and (co-)financing of health services and a certain amount of «competitive tendering» - but not to an extent that will threaten the public health services. There is political and professional disagreement, for example over the size of this private element, but little disagreement concerning the general goals.

The problem is, however, that many of the wishes of politicians as well as professionals for good health services are mutually incompatible. Queues and waiting times can disappear, the quality and cost control can be improved. There can be more equality as well as more freedom of choice. There can be fewer administrative staff, or there can be more - if the health personnel want to be relieved of this duty. There can be more professional autonomy for the individual health worker or there can be more universal guidelines that everybody is expected to follow, thus to provide equal treatment to all patients. There can be more continuity in the follow-up of the patients, or there can be more favourable work schedules for health personnel. Anything can be achieved, but not at the same time. Choices and priorities have to be made. We are not referring to simple prioritisations, such as whether or not to permit a new form of cancer treatment. Neither are we referring to how this is perceived as a battle between the good guys and the bad guys, that some are thinking exclusively of money and production, whereas others have only the best interest of the patient in mind. In the most outstanding hospitals in the USA they undoubtedly have the best interest of the patient in mind. But it comes at a cost. A hospitalisation in the USA is on average three times more costly than a hospitalisation in Norway. A stay in an outstanding hospital such as Stanford costs a lot more, but no data are publicly available. When public statistics reveal that US health services are «only» twice as expensive as Norwegian ones, this is for one reason alone: Only a fraction of the population of the USA can make use of top-shelf health services. A large proportion of the population continue to have access to only a bare minimum of health care.

A real health-policy debate involves finding answers and making choices that would impel the health services in widely different directions. Do we want publicly funded health services that provide everybody with equal treatment options? It is possible, but then the costs - and the range of available options - must be kept under control. Do we want services of the best possible quality? This is also possible, but it will be costly. Then, the available options will depend on individual ability to pay. Norway can have the world's best health services for individual patients, for the population as a whole or for the health workers - but not for all of them at the same time. That's wishful thinking. 